\title{
Electricity storage with liquid fuels in a zone powered by $100 \%$ variable renewables
}

\author{
LEONARD Grégoire ${ }^{1,3}$, FRANCOIS-LAVET Vincent ${ }^{2}$, \\ ERNST Damien ${ }^{2}$ \\ ${ }^{1}$ Department of Chemical engineering; ${ }^{2}$ Department of \\ Electrical Engineering and Computer Science \\ University of Liège \\ Liège, Belgium
}

\begin{abstract}
In this work, an electricity zone with $100 \%$ renewables is simulated to determine the optimal sizing of generation and storage capacities in such a zone. Using actual wind output data, the model evaluates the economic viability of a power-to-fuel storage technology that combines water electrolysis, $\mathrm{CO}_{2}$ capture and methanol synthesis. The main advantage of using methanol as an energy carrier is that liquid fuels are suitable for (long-term) energy storage thanks to their high energy density. The levelized electricity cost projection by 2050 equals $83.4 € / M W h$ in the base case configuration. The effects of storage round-trip efficiency and the storage unit lifetime are quantified and their impacts on the electricity cost discussed. Additional benefits of using methanol as a fuel substitute may be taken into account in further work.
\end{abstract}

Index Terms--Renewable energy sources, Wind energy integration, Energy storage, Electricity cost, Power-to-fuel

\section{INTRODUCTION}

Although the capacity of renewable sources has considerably increased in recent years in Europe, it remains far below the levels required to achieve the European Commission goals of $96-99 \%$ electricity decarbonisation by 2050 [1]. Besides hydroelectric power, wind and solar power are the main low-carbon and renewable sources that may be deployed at large-scale in European electricity markets. However, their integration into the electricity grid is complicated by the time-varying nature of these resources (hence the name "variable renewables") which does not match well with the low flexibility of most conventional power generators. Different solutions may be proposed to ensure that the generated electricity, at any point in time, equals the consumed electricity for a given electricity zone when the share of variable renewables increases. First, industrial or domestic demand-response schemes may be encouraged to increase the flexibility of demand (e.g. [2]-[3]). Second, the variability on the supply side may be addressed by improving power grid interconnections and extending the infrastructure towards a global grid [4]. Finally, both the demand and the supply can be regulated if efficient means to store and release electrical energy are developed. However, the advantages of

\author{
MEINRENKEN Christoph J. ${ }^{3}$, LACKNER Klaus S. ${ }^{3}$ \\ ${ }^{3}$ Lenfest Center for Sustainable Energy, Earth Institute, \\ Department of Earth and Environmental Engineering \\ Columbia University \\ New York City, NY, USA
}

electricity storage are difficult to quantify. From the case of Denmark and Germany, it seems that a better interconnection of the electricity zones is more economically attractive than storage in a first step [5]. However, as the integration of variable renewables keeps increasing, grid interconnection is not sufficient and energy storage becomes necessary.

The benefits of storage are numerous, ranging from arbitrage possibilities on the energy market to ancillary services such as balancing capabilities, contingency reserves or black start capabilities. In the case of a flexible storage technology that may address both energy arbitrage and reserves requirements, the benefit for installed storage capacity was estimated as $128 \$ / \mathrm{kW}$-year [6]. Considering a world in which $100 \%$ of electricity is generated by renewables with the help of storage, an average electricity cost of $142 € / \mathrm{MWh}$ was calculated based on state-of-the-art renewables and storage technologies [7]. However, the transition to such a world will not be easy because current storage technologies are not economically attractive yet in the absence of subsidies, as stated in e.g., [8] for the case of the Irish grid. This last study also showed that storage may even slightly reduce the environmental benefit of renewables if its implementation leads to a larger use of flexible mid-merit fossil-fuel power plants at the expense of inflexible base-load generators.

During the last few years, various technology options for electricity storage have attracted increasing attention. Among others, the potential of batteries, pumped hydro storage and compressed air storage has been assessed for large-scale storage. While pumped hydro storage and compressed air energy storage are better suited for electricity arbitrage (low storage costs), electro-chemical systems like batteries are better for ancillary services (short response time but high storage costs) [9]. Moreover, the importance of interseasonal electricity storage has been clearly evidenced in [10] for an energy system with $57 \%$ wind penetration, a level foreseen for Denmark by 2025 . The main reason lies in the different demand versus generation variability profiles across months. Finally, the interest in long-term storage is already present in 
current electricity markets as evidenced in [11] for the case of a storage technology using hydrogen as energy carrier.

In the present work, we propose to study a storage technology that uses electricity to produce methanol, also called power-to-fuel. A simplified scheme of the storage process is described in Figure 1, implying three main steps: $\mathrm{CO}_{2}$ capture (from air or flue gas), hydrogen production by water electrolysis and methanol synthesis from hydrogen and $\mathrm{CO}_{2}$. Stored methanol can then be converted back to electricity (via fuel cell with internal steam reforming) or used as a fuel substitute for mobile applications thanks to its high octane rating.

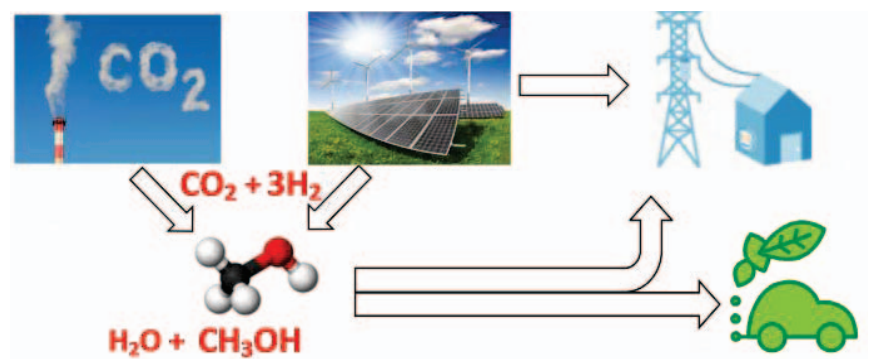

Figure 1. Scheme of the power-to-fuel process using methanol

The main advantage of liquid fuels is their high energy density: $22.4 \mathrm{MJ} / \mathrm{kg}$ for methanol [12] compared to less than $1 \mathrm{MJ} / \mathrm{kg}$ for batteries or pumped hydro storage. In terms of volume, their energy density at standard ambient conditions is also much higher $(17.8 \mathrm{MJ} / \mathrm{L})$ than for gaseous energy carriers like hydrogen or methane $(0.01$ and $0.03 \mathrm{MJ} / \mathrm{L}$ respectively). This feature makes long-term storage of liquid fuels easy and their transportation very cheap. Although its specific energy density is lower than gasoline (22.4 compared to $44.4 \mathrm{MJ} / \mathrm{kg}$ ), methanol is safer and its combustion is cleaner. Finally, if produced with the help of renewable energies and captured $\mathrm{CO}_{2}$, methanol may also be considered as a $\mathrm{CO}_{2}$-neutral energy carrier that could play a large role in decarbonisation of the transportation sector [13]. Currently, $40 \%$ of the methanol production is used for energy, but this market may well see a dramatic increase in the next decades according to Nobel laureate G. Olah who discussed the development of a "Methanol Economy" [14]. In the present work, we evaluate the potential of power-to-methanol as an energy storage technology in an electricity zone powered by $100 \%$ variable renewables.

\section{MODEL BUILDING}

A simplified model of a hypothetical electricity zone has been developed in Python 2.7. In this zone, we assume that the only primarily source for electricity generation is wind power. Some electricity can be stored in the form of methanol in order to be released at a later time-point. No market competitiveness is considered in the model, so it can be viewed as describing a state-controlled electricity zone without interaction with neighboring zones. In this section, we first discuss costs and performance assumptions for wind and power-to-methanol. Then, we present the model simulating a $100 \%$-renewable electricity zone based on Belgian historical data.

\section{A. Performance and cost parameters}

The main parameters for the wind and the storage technologies are listed in Table 1. Technical and cost data for wind and storage are projections for 2050, assuming further technology improvements and cost reductions to achieve the goal of $100 \%$ renewables. Wind data are retrieved from [16]. Regarding the power-to-fuel route, no cost estimation could be retrieved for the route including electrolysis, $\mathrm{CO}_{2}$ capture and methanol synthesis. In order to estimate these data, several assumptions were necessary. First, we consider a reversible solid oxide cell that can operate in both electrolysis and fuel cell modes as discussed in [17]. Based on [18], the efficiency of water electrolysis equals $76.8 \%$. The efficiency of the conversion of $\mathrm{CO}_{2}$ and $\mathrm{H}_{2}$ into methanol may be estimated as $80 \%$ based on own modeling results and the efficiency of electricity generation in fuel cell mode equals about $60 \%[10$, 18]. This leads to a round-trip efficiency of $37 \%$ given current available technologies. However, in the base case for 2050, we arbitrarily assume a round-trip efficiency of $50 \%$ considering further technology development and integration to reduce process losses. Energy losses related to $\mathrm{CO}_{2}$ capture are included in the price of $\mathrm{CO}_{2}$ as an operational cost.

The electrolyser cost for 2050 is estimated as $280 € / \mathrm{kW}$ Capex $+25 € / \mathrm{kW} /$ year fixed O\&M, based on $\mathrm{kW}$ of electricity input [18]. Assuming a fuel synthesis cost of $1.5 \$ / G J ~[17]$ and a dollar to euro rate of $1.15 \$ / €$, the capital cost of the methanol synthesis is calculated to $576 €$ per $\mathrm{kW}$ of storage at a methanol capacity of $246 \mathrm{t}$ methanol/year for a typical $0.25 \mathrm{MW}$ storage unit. Due to the methanol synthesis stoichiometry, the operating cost for $\mathrm{CO}_{2}$ and water is respectively $5.810^{-3}$ and $0.210^{-3} €$ per $\mathrm{kWh}$ of methanol produced (we consider a feedstock cost of $26 € /$ ton $\mathrm{CO}_{2}$ and $0.87 € / \mathrm{m}^{3}$ water [17]). Due to the model structure (electricity zone with only one, state-controlled actor), excess electricity due to any wind overcapacity is available at zero marginal cost for water electrolysis. Moreover, because of the relative ease of storing methanol at room temperature, we approximate as zero the cost of keeping energy stored over time. This cost is negligible in comparison to the cost of converting electricity into fuel (and back), which is one of the main assets of this storage technology.

TABLE I. COST PARAMETERS FOR WIND POWER AND STORAGE.

\begin{tabular}{|l|l|l|}
\hline & Wind power unit & Storage unit \\
\hline Net unit capacity & $5 \mathrm{MW}$ & $0.25 \mathrm{MW}$ \\
\hline Capex costs & $1100 € / \mathrm{kW}$ & $856 € / \mathrm{kW}$ \\
\hline Fixed O\&M costs & $\begin{array}{l}1.7 \% \text { of Capex per } \\
\text { year }\end{array}$ & $25 € / \mathrm{kW} /$ year \\
\hline Opex costs & $0 € / \mathrm{kWh}$ & $610^{-3} € / \mathrm{kWh}$ \\
\hline Lifetime & 25 years & 20 years \\
\hline Interest rate & $7 \%$ & $7 \%$ \\
\hline
\end{tabular}




\section{B. Model of an electricity zone with $100 \%$ renewables}

In order to consider the variability of the supply and of the demand based on representative data from a real electricity zone, we use historical data provided by the Belgian transmission system operator ([15]) for a three-year period (from January 19, 2012 to January 18, 2015). Two types of data are used, both with 15-minute resolution. First, instant load data represent the variability of the demand. The timeaverage load over the three-year period in our system equals $9.1 \mathrm{GW}$, varying from a minimum demand of $5.8 \mathrm{GW}$ up to a maximum of $13.4 \mathrm{GW}$. Second, instantaneous time-varying wind generation and wind capacity data are used to infer the time-varying wind capacity factor for the same zone. No distinction is made between on-shore and off-shore wind. The resulting average capacity factor over the considered period is $29 \%$, varying between a minimum capacity factor of $0.4 \%$ and a maximum of $96 \%$.

Based on these data, we compare at each time point the actual historical demand in the zone with the total power that can be generated by (i) the hypothetical installed wind power and (ii) additional methanol-to-power capacities. Whenever the power generation from wind is larger than the demand, electricity is stored via the power-to-fuel route. Whenever the generation is lower than the demand, methanol is released from the storage tank and converted back to electricity to meet the gap between demand and wind generation. For times when wind generation exceeds not only demand but also the storage capacity (i.e. the maximum power consumption of storage units), excess generation is simply assumed curtailed without adverse effects on grid stability. However, no energy curtailment occurs in the model because of a full storage tank. Indeed, we assume that each power-to-fuel unit has an arbitrarily large tank available as a consequence of the low storage cost for methanol. The model is initialized with an amount of methanol in the storage tank large enough to overcome the start-up variability of weather conditions at the beginning of data measurement. The total size of the storage tank is determined so it never becomes empty over the threeyear period.

The average cost of electricity in the zone is calculated as the sum of levelized Capex (using lifetimes and interest rates from Table 1) and Opex of wind and storage over the threeyear period, divided by the amount of electricity that is served to meet the demand during this same period. Thus, this levelized cost does not vary with time and market competitiveness is not considered. If sold at that price, that would mean that the profit achieved by generating electricity in this state-controlled zone is zero. The electricity cost as defined in this study may hence be seen as a break-even price per $\mathrm{kWh}$ that only depends on the installed capacities of wind power and storage and on the parameter assumptions discussed previously. In the present work, no profit is considered for oxygen as a by-product of water electrolysis. We also do not consider any influence of transmission and distribution limitations and we neglect the cost of grid control units that measure wind generation and dispatch storage units.

Finally, the optimization model consists in minimizing the average cost of electricity while considering two constraints. First, the installed capacity of wind power and storage combined has to be large enough to ensure that demand is served at any time. Recall that "storage capacity" refers to the maximal power input $(\mathrm{kW})$ of the power-to-fuel units, not to the size of the storage tank or "energy capacity", which is set arbitrarily large. This first constraint guarantees the reliability of the electricity zone (no blackouts due to supply shortage). In the model, this is expressed by setting to zero the maximal number of time-periods with a demand larger than the supply, this latest being a combination of wind generation and electricity released from storage. The second constraint of the system requires the amount of methanol stored at the end of the three-year period to be equal to the amount at the beginning. In other words, this second constraint ensures that the installed capacities exactly match the system requirements with no net consumption of methanol.

\section{RESULTS}

In this section, we first present the results of the base case model. Then, a sensitivity study evaluates the impact of the round-trip efficiency of the power-to-fuel route. Finally, the influence of the storage unit lifetime is assessed.

\section{A. Base Case Model}

Based on the data and assumptions described in the previous section, a unique solution can be found to the optimization problem, leading to installed wind and storage capacities of $44.6 \mathrm{GW}$ and $13.5 \mathrm{GW}$ respectively. The share of electricity that is directly served by wind equals $74.6 \%$ and the resulting electricity cost is $83.4 € / \mathrm{MWh}$. The curtailment rate of wind power is $13.3 \%$. These results highlight that although overcapacity is necessary to achieve $100 \%$ demand coverage with wind and storage, it leads to an electricity cost that is less than twice the current average electricity price in the Belgian market (45.1 €/MWh over the same period, [19]). Increasing the storage power capacity would decrease the curtailment rate, but at the expense of a higher average cost of electricity. In practice, this should however be considered if the excess methanol production can be valorized for other uses than electricity generation, which has been neglected in the present model.

Figure 2 represents the evolution of the storage level with time in the base case configuration. As already discussed, the size of the storage tank is defined so there is no limitation on the amount of energy that can be stored and we assume that the amount stored at the beginning of the three-year period is high enough to remove the start-up variability. Large patterns appear in the storage level over time, evidencing months with higher energy availability like between day 220 and day 500 for instance, as well as months where energy is almost only released from the storage tank like between day 800 and day 1000. Note that the energy availability is related to the combination of wind availability and demand requirement. As a consequence, the relevance of a storage technology that is able to convert power into an energy carrier that is easy and cheap to store over long-term periods is evidenced. Indeed, it appears clearly that the storage level varies according patterns of about 200 days, corresponding to interseasonal fluctuations of about 6-7 months. If storage limitations and costs are negligible as discussed in the present work for the power-tofuel route, such a technology would thus accumulate energy 
during high energy availability seasons and release it during low availability seasons.

From Figure 2, it also appears that the maximum level of energy stored over the three-year period equals about $10 \mathrm{TWh}$ (accounted in terms of net electricity released from the storage tank). This may be compared to the size of the largest pumphydro storage unit in Belgium (Coo hydropower plant) which has an energy capacity of about 5.8 GWh [20]. It appears that the maximum storage level identified in our model based on historical Belgian data is one order of magnitude above this value. As a consequence, this result evidences that the need for energy storage would be far beyond the current available capacity if the transition to an electricity zone powered with $100 \%$ variable renewables should happen now.

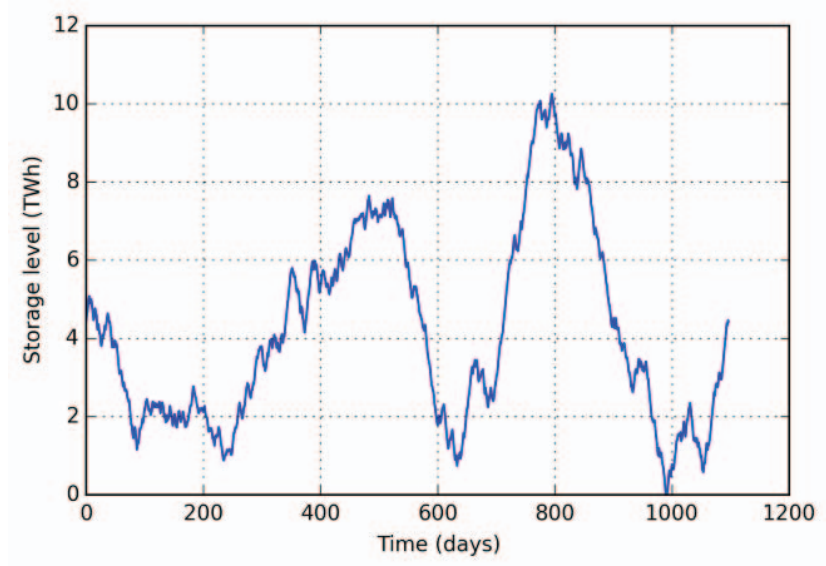

Figure 2. Evolution of storage level (base case).

\section{B. Sensitivity to round-trip efficiency}

One of the main research fields for improving electrolysers is the development of high-efficiency devices to reduce the conversion losses at high current densities. In Figure 3, we evaluate the impact of the round-trip efficiency of the powerto-fuel system.

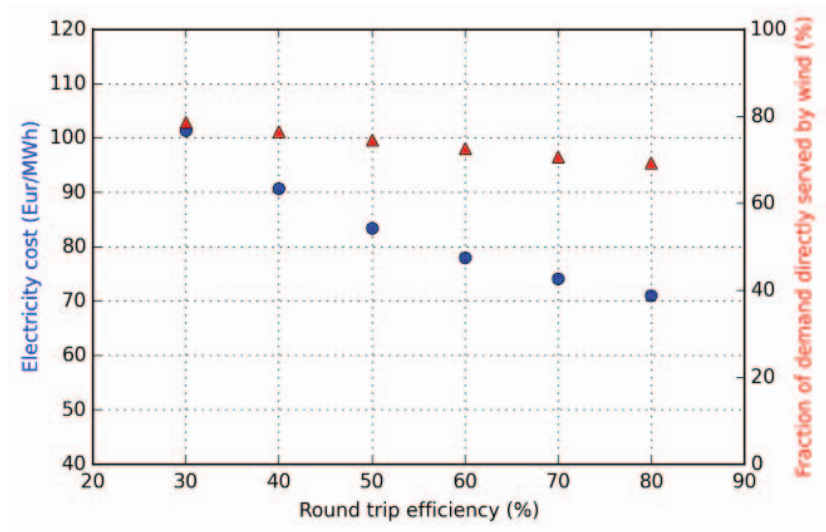

Figure 3. Electricity cost as function of storage round-trip efficiency.
Note that the base case configuration used a value of $50 \%$ for the round-trip efficiency, while the current state-of-the art may be closer to $37 \%$ as discussed in Section II. As expected, the optimum configuration shifts towards less wind and more storage capacity when storage units become more efficient. The cost of electricity decreases at higher efficiencies. For instance, doubling the efficiency from $40 \%$ to $80 \%$ decreases the electricity cost by $22 \%$ from $90.7 € / \mathrm{MWh}$ down to $71.0 € / \mathrm{MWh}$. This also strongly decreases the energy losses (curtailment rate from $14.3 \%$ down to $6.5 \%$ ). However, the cost savings are due to lower capacity requirements for wind and storage rather than to the reduction of energy losses since we assumed that the marginal cost of excess wind electricity is zero. All in all, the storage round-trip efficiency appears as an important factor in determining the average price of electricity since each point of efficiency increase leads to a reduction of the electricity cost equivalent to about $0.6 € / \mathrm{MWh}$, varying from $1 € / \mathrm{MWh}$ at low efficiencies to $0.3 € / \mathrm{MWh}$ at high efficiencies.

\section{Sensitivity to storage lifetime}

Many unknowns still exist regarding the lifetime of solid oxide electrolysers. For instance, issues due to degradation within the cell at high current densities have been reported [17] and need to be addressed. We thus study the impact that the lifetime of a typical power-to-fuel unit may have on the electricity cost in Figure 4 (base case used 20 years).

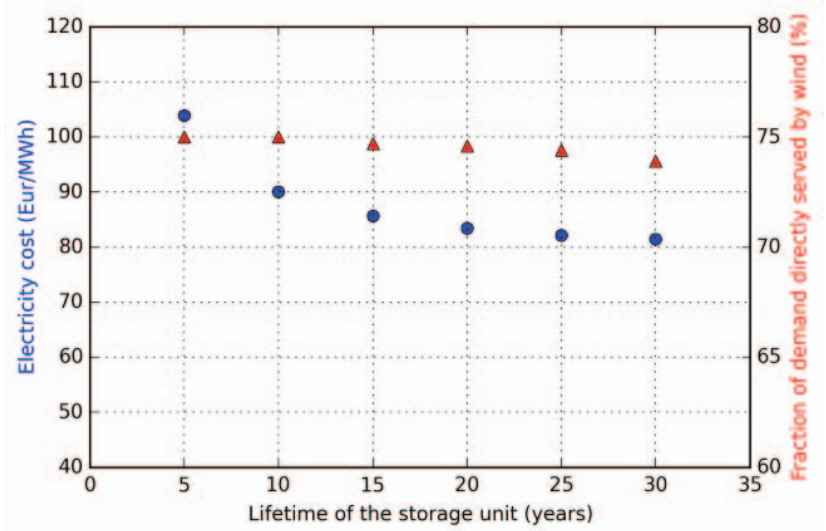

Figure 4. Electricity cost as function of the storage lifetime.

As expected, the share of wind in serving the demand slightly decreases when the lifetime of storage increases. This leads to a decrease of the system Capex. Indeed, the power-tofuel route becomes more profitable and replaces some of the wind capacity, similarly to what was observed at high roundtrip efficiencies. However, the cost reduction diminishes as the lifetime keeps on increasing. Increasing the lifetime from 15 to 30 years only decreases the cost of electricity by $5 \%$ from 85.6 to $81.4 € / \mathrm{MWh}$. In comparison, improving the lifetime from 5 to 10 years decreases the cost by $14 \%$ (104.9 to $90.0 € / \mathrm{MWh}$ ). This diminishing impact may be related to the gradually lower influence of the lifetime increase on the Capex amortization. 


\section{CONCLUSION}

In the present work, we evaluate the potential of a powerto-fuel storage technology in a state-controlled electricity zone where power is generated by variable renewables and energy release from storage only. The storage technology we consider combines $\mathrm{CO}_{2}$ capture, water electrolysis and methanol synthesis to produce a $\mathrm{CO}_{2}$-neutral liquid fuel that is, as a high-density energy carrier, very cheap to store, even on a long-term basis. Another advantage (not evaluated in the present work) is the flexibility of use offered by liquid fuels, as they can be used either to generate electricity or as fuel substitute for mobile applications, with the potential to contribute to decarbonize the electricity and transportation sectors

The costs of such a storage technology are evaluated based on literature data and included into the electricity zone model. This model takes into account the demand and wind supply variabilities based on historical data from the Belgian transmission system operator covering a period of three years. We find that electricity can be produced in this zone with $100 \%$ renewables at a cost that is about twice the current average electricity price on the Belgian day-ahead market. Moreover, seasonal patterns of approximately six-month length clearly appear in the level evolution of the storage tank, showing the relevance of a power-to-fuel technology with negligible long-term storage costs. Two important parameters of the storage technology, i.e. the round-trip efficiency and the lifetime are varied and their impacts on the cost of electricity are quantified. Cost savings achieved at higher round-trip efficiencies stem from lower capital costs (per energy output) due to improved system configuration. Increasing the storage unit lifetime also reduces the electricity cost but this effect strongly diminishes as the lifetime increases above 15 years.

In future work, further cost reductions may be achieved by considering a higher capacity factor for on-shore wind. An average value of $45 \%$ is foreseen by 2050 according to [16]. This is much higher than the average capacity factor of $29 \%$ obtained from historical data in the present model. The valorization of excess methanol as a fuel substitute may also be considered, thus further improving the profitability of the power-to-fuel storage. Thus, the electricity costs discussed in the present work may be seen as upper bounds for the cost of electricity in 2050. Further work may evaluate the impact of costs assumptions (Capex, Opex, interest rate, etc.) on the system optimum, as well as they may study the cost of system reliability by relaxing the constraint of $100 \%$ demand coverage. The influence of market competitiveness in the electricity zone may also be studied, leading to a variable electricity price at each time period. Other renewables like solar and hydro power may then be included into the model. This will lead to a configuration closer to the reality with lower supply variability (and thus a smaller need for storage) thanks to the different generation time profiles of these variable renewables.

\section{ACKNOWLEDGMENTS}

G. Léonard is an honorary fellow of the Belgian American Educational Foundation and his research is supported by the
"Wallonie-Bruxelles International" Agency and by a Rotary District Scholarship (District 1630).

\section{REFERENCES}

[1] European Commission, "Energy roadmap 2050," Publication Office of the European Union, Luxembourg, 2012. doi:10.2833/10759.

[2] M. Zheng, C.J. Meinrenken and K.S. Lackner, "Agent-based model for electricity consumption and storage to evaluate economic viability of tariff arbitrage for residential sector demand response," Applied Energy, vol. 126, pp. 297-306, 2014.

[3] M. Zheng, C.J. Meinrenken and K.S. Lackner, "Smart households: Dispatch strategies and economic analysis of distributed energy storage for residential peak shaving," Applied Energy, in press.

[4] S. Chatzivasileiadis, D. Ernst and G. Andersson, "Global power grids for harnessing world renewable energy," in Renewable Energy Integration : Practical Management of Variability, Uncertainty and Flexibility in Power Grids, L. E. Jones, Ed., Academic Press, 2014, pp. 175-188.

[5] R. Bove, M. Bucher and F. Ferretti, "Integrating large shares of wind energy in macro-economical cost-effective way," Energy, vol.43, pp. 438-447, 2012.

[6] P. Denholm, J. Jorgenson, M. Hummon, T. Jenkin, D. Palchak, B. Kirby, O. Ma and M. O’Malley, "The value of energy storage for grid applications," National Renewable Energy Laboratory, US DOE, Oak Ridge, TN, USA, Technical Report NREL/TP-6A20-58465, May 2013.

[7] G. Pleßman, M. Erdmann, M. Hlusiak and C. Breyer, "Global energy storage demand for a 100\% renewable electricity," Energy Procedia, vol. 46, pp. 22-31, 2014.

[8] B. Nyamdash, E. Denny and M. O'Malley, "The viability of balancing wind generation with large scale energy storage," Energy Policy, vol. 38, pp. 7200-7208, 2010.

[9] C.K. Ekman and S.H. Jensen, "Prospects for large scale electricity storage in Denmark," Energy conversion and Management, vol. 51, pp. 1140-1147, 2010.

[10] K. Hedegaard and P. Meibom, "Wind power impacts and electricity storage - A time scale perspective," Renewable Energy, vol. 37, pp. 318-324, 2012.

[11] V. François-Lavet, R. Fonteneau and D. Ernst, "Using approximate dynamic programming for estimating the revenues of a hydrogen-based high-capacity storage device," in Adaptive Dynamic Programming and Reinforcement Learning (ADPRL), 2014 IEEE Symposium, pp 1-8.

[12] E. Fiedler, G. Grossmann, D. Kersebohm, G. Weiss and C. Witte, "Methanol," in Ullmann's Encyclopedia of Industrial Chemistry, Weinheim: Wiley-VCH Verlag GmbH \& Co. KGaA, 2005, p 18.

[13] C.J. Meinrenken and K.S. Lackner, "Options to dissociate $\mathrm{CO}_{2}$ and $\mathrm{H}_{2} \mathrm{O}$ for sustainable sunlight-to-fuel pathways," Journal of Natural Sciences, vol. 2, 2014.

[14] G. Olah, "Beyond oil and gas: the methanol economy," Angewandte Chemie International Edition, vol. 44, pp. 2636-2639, 2005.

[15] Elia, Belgium's electricity transmission system operator, Grid data. Available: http://www.elia.be/en/grid-data

[16] JRC Science and Policy Reports, "Energy technology reference indicator projections for 2010-2050," Institute for Energy and Transport, Joint Research Centre, European Commission, 2014.

[17] C. Graves, S. Ebbesen, M. Mogensen and K. Lackner, "Sustainable hydrocarbon fuels by recycling $\mathrm{CO}_{2}$ and $\mathrm{H}_{2} \mathrm{O}$ with renewable or nuclear energy," Renewable and Sustainable Energy Reviews, vol. 15, pp. 1-23, 2011.

[18] B. V. Mathiesen, I. Ridjan, D. Connolly, M.P. Nielsen, P. V. Hendriksen, M. B. Mogensen, ... and S.D. Ebbesen, "Technology data for high temperature solid oxide electrolyser cells, alkali and PEM electrolysers," Department of Development and Planning, Aalborg University, 2013.

[19] Belpex, Belgium's day-ahead market for electricity, Market data. Available: https://www.belpex.be/market-results/historical-data/

[20] GDF SUEZ, Installed hydropower capacity in Belgium at the CooTrois-Ponts pumped storage hydroelectric plant. http://www.gdfsuez.com/en/businesses/electricity/hydropower/ 